\title{
Protocolos e condutas para diferentes situações clínicas de avulsão de dentes permanentes
}

Protocols and procedures for different clinical situations of avulsion of permanent teeth

Protocolos y procedimientos para diferentes situaciones clínicas de avulsión de dientes permanentes

Luciana de Oliveira Souza PEDROSA ${ }^{1}$

Adriano Referino da SILVA SOBRINHO²

Renata de Oliveira CARTAXO'

${ }^{1}$ Cirurgiã-dentista graduada pelo Curso de Bacharelado em Odontologia da Universidade Estadual da Paraíba (UEPB), Centro de Ciências, Tecnologia e Saúde, Campus VIII, 58233 - 000 Araruna - PB, Brasil

${ }^{2}$ Curso de Bacharelado em Odontologia da Universidade de Pernambuco (UPE) campus Arcoverde, 56512-200 Arcoverde-PE, Brasil

\begin{abstract}
Resumo
Introdução: O traumatismo dentário é frequente nos serviços de urgência Odontológica. A avulsão dentária, como parte desse grupo de lesões, é comum em crianças e jovens, e possui como principais causas acidentes esportivos e automobilísticos. O cirurgião-dentista deve conhecer os protocolos para conduzir os casos de avulsão dentária, bem como orientar os pacientes sobre como proceder nestas situações. Objetivo: Realizar uma revisão de literatura acerca dos protocolos e condutas em diferentes situações de avulsão dentária. Material e método: Foi realizada uma busca de artigos através dos descritores "Avulsão Dentária", "Conduta clínica" e "Reimplante dentário" na base de dados da Biblioteca Virtual de Saúde nos idiomas inglês e português, tendo como critérios de inclusão estudos que possuem condutas diante de situações de avulsão. Resultados: O tratamento de escolha para a avulsão dentária é o reimplante do elemento. As condições de armazenamento e tempo fora do alvéolo são fatores decisivos no sucesso do reimplante dentário e este deve ser realizado no local do acidente. Nos casos em que não for possível o reimplante imediato, o elemento dentário deve ser acondicionado em meio adequado para preservar a vitalidade pulpar e do ligamento periodontal. O reimplante tardio pode ser uma alternativa para os casos onde objetiva-se a preservação do osso alveolar para posterior implante dentário. Conclusão: Ressalta-se a necessidade de discussão sobre o tema entre cirurgiões dentistas, profissionais da saúde e da educação, a fim de disseminar conhecimento e contribuir para a adoção de melhores condutas frente a casos de avulsão dentária.
\end{abstract}

Descritores: Traumatismos Dentários; Avulsão Dentária; Reimplante Dentário; Protocolos Clínicos.

\section{Abstract}

Introduction: Dental trauma is quite common in emergency dental services. Tooth avulsion, as part of this group of injuries, is quite common in children and young people and its main causes are sports and automobile accidents. The dentist must know the protocols to manage dental avulsion cases, as well as guide patients on how to proceed in these situations. Objective: To perform a literature review on the protocols and procedures in different situations of dental avulsion. Material and method: A search for articles was performed using the descriptors "Dental Avulsion", "Clinical conduct" and "Dental replantation" in the database of the Virtual Health Library in English and Portuguese, with inclusion criteria as studies that have conducts in the face of situations of avulsion. Results: The treatment of choice for dental avulsion is the replantation of the element. The conditions of storage and time outside the socket are decisive factors in the success of dental replantation and this must be carried out at the accident site. In cases where immediate reimplantation is not possible, the dental element must be placed in an appropriate environment to preserve the pulpal and periodontal ligament vitality. Late replantation may be an alternative for cases where the objective is to preserve the alveolar bone for subsequent dental implantation. Conclusion: The need for discussion on the topic among dental surgeons, health and education professionals is emphasized, in order to disseminate knowledge and contribute to the adoption of better conducts in cases of dental avulsion.

Descriptors: Tooth Injuries; Tooth Avulsion; Tooth Replantation; Clinical Protocols.

\section{Resumen}

Introducción: El trauma dental es bastante común en los servicios dentales de emergencia. La avulsión dental, como parte de este grupo de lesiones, es bastante común en niños y jóvenes y sus principales causas son los accidentes deportivos y automovilísticos. El dentista debe conocer los protocolos para manejar los casos de avulsión dental, así como guiar a los pacientes sobre cómo proceder en estas situaciones. Objetivo: realizar una revisión de la literatura sobre los protocolos y procedimientos en diferentes situaciones de avulsión dental. Material y método: Se realizó una búsqueda de artículos utilizando los descriptores "Avulsión dental", "Conducta clínica" y "Replantación dental" en la base de datos de la Biblioteca Virtual en Salud en inglés y portugués, con criterios de inclusión como estudios que tienen conductas ante situaciones de avulsión. Resultados: El tratamiento de elección para la avulsión dental es la reimplantación del elemento. Las condiciones de almacenamiento y el tiempo fuera del receptáculo son factores decisivos para el éxito de la reimplantación dental y esto debe llevarse a cabo en el lugar del accidente. En los casos en que no sea posible el reimplante inmediato, el elemento dental debe colocarse en un ambiente apropiado para preservar la vitalidad de la pulpa y el ligamento periodontal. La reimplantación tardía puede ser una alternativa para los casos en que el objetivo es preservar el hueso alveolar para su posterior implante dental. Conclusión: Se enfatiza la necesidad de discusión sobre el tema entre los cirujanos dentales, los profesionales de la salud y la educación, para difundir el conocimiento y contribuir a la adopción de mejores conductas en casos de avulsión dental.

Descriptores: Traumatismos de los Dientes; Avulsión de Diente; Reimplante Dental; Protocolos Clínicos.

INTRODUÇÃO

O traumatismo dentoalveolar é um conjunto de lesões que afetam os dentes e suas estruturas de suporte. É umas das principais causas de ocorrências nas urgências odontológicas, constituindo grande problemática entre crianças e adolescentes ${ }^{1,2}$. A avulsão dentária é considerada o tipo de traumatismo mais grave e se caracteriza pelo deslocamento total do dente para fora do alvéolo, o que pode causar danos em estruturas como ligamento periodontal, osso alveolar, cemento e polpa do dente ${ }^{3}$.

Diante de sua magnitude, a avulsão dentária afeta diretamente a qualidade de vida, a aparência, a autoestima, a dicção e o posicionamento dos dentes, podendo causar problemas físicos, emocionais, estéticos e afetar 0 relacionamento social das pessoas ${ }^{4}$. 
Os protocolos de tratamento devem ser conduzidos no sentido de promover, sempre que possível, a manutenção da vitalidade do dente avulsionado mediante procedimentos estabelecidos no pré e pós-tratamento ${ }^{1}$. O tratamento de primeira escolha é, portanto, o reimplante imediato do dente permanente avulsionado, e, quando isso não for possível, deve-se acondicionar 0 dente em meio apropriado $^{5}$ até que existam condições adequadas para recolocação do dente no alvéolo.

Frente ao exposto e diante da diversidade de situações clínicas que podem ocorrer envolvendo a avulsão de dentes permanentes, torna-se relevante conhecer as melhores condutas propostas para cada situação específica de avulsão dentária. Assim, o objetivo deste trabalho foi revisar a literatura acerca dos protocolos e condutas clínicas para diferentes situações de avulsão traumática de dentes permanentes.

MATERIAL E MÉTODO

O levantamento dos dados contidos nesta revisão da literatura foi realizado por meio de busca na Biblioteca Virtual em Saúde e a partir de informações da Associação Internacional de Traumatologia Dentária1. Foram selecionados artigos em português e inglês publicados nos últimos 20 anos, abrindose exceção para inclusão de trabalhos clássicos sobre o tema, priorizando as publicações que traziam consigo protocolos e condutas clínicas. As palavras-chave utilizadas para a seleção dos artigos foram: Avulsão Dentária "and" Condutas Clínicas, Avulsão Dentária "and" Reimplante Dentário, Tooth Avulsion and Conducts Clinics, Tooth Avulsion and Dental Replantation.

A revisão de literatura deste trabalho foi redigida na forma conduta clínica e procedimentos, com o objetivo de se tornar um guia atualizado de fácil acesso e consulta para os profissionais da saúde. Os resultados foram apresentados no formato de tabela didática para melhor sistematização das informações relevantes.

RESULTADOS E DISCUSSÃO

\section{- Descrição}

A avulsão dentária caracteriza-se pelo completo deslocamento do dente para fora de seu alvéolo, o qual permanece vazio ou preenchido com um coágulo. Para a sua confirmação, deve ser realizada um completo exame clínico completo, inclusive exames radiográficos de rotina, como as radiografias oclusal e periapical ${ }^{6}$.

A avulsão dentária ocasiona severo dano ao seu suprimento vásculo-nervoso, podendo ocorrer necrose pulpar. O ligamento periodontal que permanece aderido às paredes do alvéolo tem a sua vitalidade preservada e não necessita de nenhum tratamento. Contudo, as fibras periodontais que ficam presas à porção radicular do dente, e que entram em contato com o ambiente externo, apresentam risco de necrose ${ }^{7}$.

\section{- Fatores etiológicos e distribuição}

As principais causas da avulsão dentária estão relacionadas à prática de esportes e acidentes automobilísticos. Para o acometimento de dentes permanentes, existe uma predominância pelo sexo masculino $0^{4,8-10}$. A prevalência de avulsão dentária varia entre 0,5 a $16,0 \%$, principalmente na faixa etária de 7 a 14 anos decorrente da presença de um ligamento periodontal mais frágil e incompleta formação radicular de dentes jovens ${ }^{8}$.

Os dentes mais acometidos por este tipo de trauma são os incisivos superiores devido à sua localização na arcada dentária, que os torna mais susceptíveis à absorção de um impacto traumático e presença de raiz única, ${ }^{9,11,12}$. Dentre os fatores que predispõem à ocorrência de avulsão dentária frente a um impacto traumático, crianças que possuem um "overjet" acentuado ou protrusão dos incisivos superiores, ausência de selamento labial, hiperatividade e obesidade, estão mais sujeitas a essas lesões traumáticas ${ }^{13}$.

\section{- Manejo do paciente traumatizado}

Os cirurgiões-dentistas devem estar sempre preparados para fornecer o aconselhamento adequado à população a respeito dos primeiros socorros para dentes avulsionados. As orientações fornecidas devem objetivar a tranquilização do paciente e o manejo adequado do dente ${ }^{8}$. Esse pode ser um fato decisivo no prognóstico do dente, devido ao fato da conduta tomada diante desse tipo de acidente ser muito influenciada pelo conhecimento do acompanhante do paciente.

Considerando a faixa etária citada anteriormente, os locais mais comuns onde os acidentes têm ocorrido são os ambientes residenciais e escolares ${ }^{14}$. A capacitação sobre manejo de traumatismos dentários para pais e responsáveis, e profissionais que lidam diariamente com eles, como os educadores, pode configurar-se como uma estratégia válida para que as condutas adequadas sejam tomadas ${ }^{5,15-17}$.

- Condutas frente ao dente avulsionado

Após a localização do dente avulsionado, deve-se analisar as circunstâncias em que o mesmo se encontra. Em seguida, 
encorajar o responsável ou quem estiver próximo a situação a reposicionar o dente no seu alvéolo e pedir que o paciente morda um lenço para que o dente reimplantado permaneça na posição até a sua condução a um serviço de urgência odontológico ${ }^{18}$.

Dentes decíduos avulsionados não devem ser reimplantados, uma vez que podem causar lesões ao germe do dente permanente, pois o coágulo pode forçar a área do folículo causando danos ao sucessor, como uma hiperplasia de esmalte reabsorção inflamatória, anquilose, infecção e exfoliação ${ }^{19}$.

\section{- Armazenamento do dente avulsionado}

Quando não for possível reimplantar o dente no local do acidente, por exemplo, quando o paciente estiver inconsciente, deve-se colocar o dente em um meio de armazenamento adequado. O dente avulsionado não deve ser mantido em um ambiente seco devido ao risco de necrose celular e estimulação de processos inflamatórios ${ }^{20}$.

Uma substância ideal para acondicionar dente avulsionado precisa ser eficaz para manter a vitalidade das células do ligamento periodontal e polpa, apresentar $\mathrm{pH}$ neutro e osmolaridade fisiológica compatível, como também ser de fácil acesso a população e ter baixo custo $^{21}$. É recomendável 0 armazenamento nas seguintes soluções, por ordem preferencial: Viaspan®, solução de Hanks, leite, soro fisiológico, saliva ou água ${ }^{22}$. 0 leite apresenta-se como o melhor meio para armazenamento a curto prazo (menos que 2 horas) devido a sua disponibilidade. Porém, o Viaspan® e a solução de Hanks ainda se apresentam como as melhores opções para armazenamento a longo prazo ${ }^{23}$. O Quadro 1 resume as vantagens e desvantagens de cada meio de armazenamento para dentes avulsionados.

O dente também pode ser transportado na cavidade oral do paciente entre a região alveolar e o fundo do vestíbulo, desde que ele esteja lúcido e orientado, mas no caso de paciente muito jovem deve-se induzir o paciente a expelir a saliva em um recipiente adequado para armazenamento do dente, para se evitar acidentes como aspiração e deglutição ${ }^{24}$.

\section{- Protocolos clínicos para o tratamento}

O tratamento de primeira escolha para dentes permanentes avulsionados consiste no reimplante dentário imediato. Porém, alguns fatores devem ser levados em conta ao decidir o melhor tratamento. Fatores como cáries e doença periodontal severas no dente; paciente não-cooperativo; e condições sistêmicas do paciente, como imunossupressão e problemas cardíacos graves, influenciam no prognóstico do dente reimplantado ${ }^{1}$. Outros fatores contribuem para o prognóstico, dentre os quais o estágio de formação radicular, o tratamento endodôntico e a imobilização ${ }^{10,28}$, além do período em que o dente permaneceu fora do alvéolo e o meio onde foi armazenado ${ }^{26}$. A taxa de sucesso do reimplante de dentes avulsionados gira em torno de $50 \%$ após 5,5 anos $^{10}$.

Quadro 1. Vantagens e desvantagens das substâncias usadas para armazenamento do dente avulsionado.

\begin{tabular}{|c|c|c|}
\hline Substância & Vantagens e desvantagens & Autores \\
\hline Viaspan & $\begin{array}{l}\text { Vantagem: mantém o dente } \\
\text { hidratado e a vitalidade dos tecidos } \\
\text { do ligamento periodontal por até } 12 \\
\text { horas; } \\
\text { Desvantagem: difícil acesso pela } \\
\text { população }\end{array}$ & $\begin{array}{l}\text { Sayão Maia et al. }{ }^{22} \\
\text { (2006); } \\
\text { Peixoto et al. }{ }^{25} \text { (2013) }\end{array}$ \\
\hline $\begin{array}{l}\text { Solução de } \\
\text { Hanks }\end{array}$ & $\begin{array}{l}\text { Vantagem: mantém o dente } \\
\text { hidratado e a vitalidade dos tecidos } \\
\text { do ligamento periodontal por até } 24 \\
\text { horas; } \\
\text { Desvantagem: difícil acesso pela } \\
\text { população }\end{array}$ & $\begin{array}{l}\text { Sayão Maia et al. }{ }^{22} \\
\text { (2006); } \\
\text { Peixoto et al. }{ }^{25}(2013) ; \\
\text { Qian et al. }{ }^{20}(2018)\end{array}$ \\
\hline Leite & $\begin{array}{l}\text { Vantagens: mantém o dente } \\
\text { hidratado pH, osmolaridade e fator } \\
\text { de crescimento epitelial adequados, o } \\
\text { que diminui o risco de morte celular } \\
\text { e minimiza a possibilidade de } \\
\text { anquilose; conaras possui baixa } \\
\text { contaminaçáo; e é de fácil acesso à } \\
\text { população; } \\
\text { Desvantagem: perde a eficácia em } 2 \\
\text { horas }\end{array}$ & $\begin{array}{l}\text { Moradian et al.7 } \\
(2013) ; \\
\text { Coste et al. }{ }^{10}(2020)\end{array}$ \\
\hline Soro fisiológico & $\begin{array}{l}\text { Vantagem: mantém o dente } \\
\text { hidratado, pH e osmolaridade } \\
\text { adequados. Aumenta as chances de } \\
\text { manutenção da vitalidade } \\
\text { periodontal; } \\
\text { Desvantagem: não contém íons que } \\
\text { sejam compativeis para a sobrevida } \\
\text { celular e com isso o ideal é } \\
\text { armazenar por apenas } 4 \text { horas }\end{array}$ & $\begin{array}{l}\text { Poi et al. }{ }^{21} \text { (2013); } \\
\text { Wang et al. }{ }^{26}(2019) \text {. }\end{array}$ \\
\hline Saliva & $\begin{array}{l}\text { Vantagem: mantém o dente } \\
\text { hidratado e previne a } \\
\text { desmineralização da coroa. } \\
\text { Desvantagens: pode conter } \\
\text { microrganismos, pH e osmolaridade } \\
\text { não adequados para o tecido do } \\
\text { ligamento periodontal }\end{array}$ & $\begin{array}{l}\text { Diangelis e Bakland }{ }^{27} \\
\text { (1998); } \\
\text { Sayão Maia et al. }{ }^{22} \\
\text { (2006); } \\
\text { Moradian et al.7 } \\
\text { (2013) }\end{array}$ \\
\hline Água & $\begin{array}{l}\text { Vantagem: mantém o dente } \\
\text { hidratado. } \\
\text { Desvantagens: pode conter } \\
\text { microrganismos, além de provocar } \\
\text { lise celular do ligamento periodontal } \\
\text { por ser uma condição hipotônica }\end{array}$ & $\begin{array}{l}\text { Diangelis e Bakland }{ }^{27} \\
\text { (1998); } \\
\text { Sayão Maia et al. }{ }^{22} \\
\text { (2006); } \\
\text { Moradian et al. }{ }^{7} \\
\text { (2013); } \\
\text { Poi et al. }{ }^{21} \text { (2013) }\end{array}$ \\
\hline
\end{tabular}

Uma vez que o dente foi reimplantado, a sua remoção não é indicada, já que possivelmente isso dificultaria o processo de cicatrização já iniciado ${ }^{1,6}$. É importante que as paredes do alvéolo não sejam raspadas, porque isto removeria os fragmentos remanescentes do ligamento periodontal, diminuindo as chances de um bom prognóstico.

Quando se parte para a conduta frente a avulsões em dentes com rizogênese incompleta, o protocolo tem o objetivo de revascularização pulpar, mantendo a sua vitalidade e integridade. Caso haja revitalização, acompanhar periodicamente para evitar futuros problemas. Em casos de não revitalização, a terapia endodôntica é necessária após determinado tempo. $O$ período entre 0 reimplante e tratamento endodôntico permite tempo suficiente para 0 processo de cicatrização e o ligamento periodontal estarem em condição favorável para suportar o estresse mecânico da terapia endodôntica ${ }^{1,6}$. 
A terapia com antibiótico é considerada essencial para prevenção da invasão por bactérias em necrose pulpares e nas possíveis reabsorções inflamatórias ${ }^{6,29}$. A Tetraciclina é o antibiótico de escolha. Porém, o risco de descoloração dos dentes em pacientes jovens deve ser levado em conta na hora da escolha do fármaco. Uma alternativa é o uso de Penicilina $V$ ou Amoxicilina ${ }^{1,30}$.

Quando o dente permanece fora do alvéolo, em ambiente desidratado, por um período superior a 60 minutos é possível esperar um prognóstico não favorável. Neste caso, a conduta requer a utilização solução de soro fisiológico e fluoreto de sódio, objetivando desacelerar o processo de reabsorção radicular e reduzir a substituição óssea ${ }^{31}$. Flores et al. $^{32}$ recomendam utilização desta técnica no reimplante tardio. Estudos in vitro e in vivo trazem 0 alendronato (bisfosfonato) como medicamento promissor para o tratamento de reabsorções dentárias de dentes que sofreram avulsão. É possível que uma associação do tratamento com fluoreto de sódio associado ao uso de medicamento do tipo bisfosfonato pode melhorar o prognóstico de dentes implantados tardiamente $^{33}$.

Uma vez necrosado, o tecido do ligamento estará perdido. Nessa situação, a terapia endodôntica pode ser feita antes ou após o reimplante, utilizando-se contenção. Nesses casos, o tratamento endodôntico deve ser mais criterioso, e a utilização de hidróxido de cálcio como medicação intracanal é indicada. Essa conduta visa minimizar a reabsorção inflamatória, já que o hidróxido de cálcio possui boas propriedades antimicrobianas, antinflamatória e de indução de reparo ósseo. Posteriormente deve-se realizar a obturação do canal radicular com guta-percha ${ }^{1,29}$.

$O$ reimplante tardio ainda pode-se ser uma opção quando se objetiva induzir o crescimento ósseo para uma futura substituição do dente avulsionado por um implante. Tal técnica ainda permite preservar a estabilidade e posição funcional do elemento perdido no arco dentário por um período longo ${ }^{34}$.

Após o reimplante do dente avulsionado, ainda é necessário o uso de contenções. Estas permitem a imobilização do dente durante 0 período inicial, fundamental para a recuperação do ligamento periodontal, sendo o tipo semirígido preferível ao rígido. Contudo, longos períodos de uso das contenções são contraindicados devido a possibilidade de reabsorção ou aquilose ${ }^{35}$.

O Quadro 2 apresenta as variadas circunstâncias necessárias para a tomada de decisão e os protocolos clínicos a serem seguidos.

Quadro 2. Condutas clínicas adequadas frente à avulsão dentária considerando o estágio de desenvolvimento radicular do dente.

\begin{tabular}{|c|c|c|}
\hline Situação & Conduta & Autores \\
\hline \multirow{2}{*}{$\begin{array}{l}\text { Dente } \\
\text { reimplantado no } \\
\text { local do acidente e } \\
\text { procura } \\
\text { atendimento por } \\
\text { imediato }\end{array}$} & $\begin{array}{l}\text { Rizogênese completa: lavar com água } \\
\text { ou clorexidina a } 12 \% \text {, verificar } \\
\text { posição e possíveis fraturas (exame } \\
\text { clínico e radiográfico), esplintagem } \\
\text { flexível ( } 1 \text { a } 2 \text { semanas) e tratamento } \\
\text { endodôntico (entre o } 7^{\circ} \text { e o } 10^{\circ} \text { dia) }\end{array}$ & \multirow[t]{2}{*}{$\begin{array}{l}\text { Xavier et al. }{ }^{6}(2013) \\
\text { Andersson et al. } \\
(2017) ; \\
\text { Veras et al. }{ }^{1} \text { (2017) }\end{array}$} \\
\hline & $\begin{array}{llr}\text { Rizogênese incompleta: verificar } \\
\text { posição do dente, } \\
\text { flexplivel (2 semanas), monitoramemento } \\
\text { da condição pulpar } & \text { (polpa nãa } \\
\text { revitalizada } & \rightarrow & \text { tratamento } \\
\text { endodôntico) } & \end{array}$ & \\
\hline \multirow{2}{*}{$\begin{array}{l}\text { Dente armazenado } \\
\text { em solução } \\
\text { adequada e busca } \\
\text { por atendimento, } \\
\text { para reimplante, } \\
\text { antes de 60 } \\
\text { minutos }\end{array}$} & $\begin{array}{l}\text { Rizogênese completa: lavar raiz com } \\
\text { soro fisiológico (segurando pela } \\
\text { coroa), anestesia, remoção do } \\
\text { coágulo (sem raspar as paredes do } \\
\text { alvéolo), verificar presença de fratura } \\
\text { alveolar, reimplante com pressão } \\
\text { digital suave, exame radiográfico } \\
\text { (para verificar a posição do dente), } \\
\text { esplintagem flexivel (2 emanas), } \\
\text { terapia antibiótica (Tetraciclina por } 7 \\
\text { dias, ou Penicilina V/Amoxicilina por } \\
\text { 4-7 dias) e terapia endodôntica }\end{array}$ & \multirow{2}{*}{$\begin{array}{l}\text { Pozo et al. } .^{6}(2006) ; \\
\text { Rodrigues et al.37 } \\
\text { (2010); } \\
\text { Siqueira, Gonçalves } 29 \\
\text { (2012); } \\
\text { Xavier et al. }{ }^{6}(2013) ; \\
\text { Hamanaka et al. } .^{0} \\
\text { 2017; } \\
\text { Veras et al. } 35 \text { (2017) }\end{array}$} \\
\hline & $\begin{array}{l}\text { Rizogênese incompleta: limpeza com } \\
\text { soro fisiológico, imersão por } 5 \\
\text { minutos em minociclina ou } \\
\text { doxiciclina (1 mg por 20 ml de } \\
\text { salina), anestesia, verificar presença } \\
\text { de fratura alveolar, realizar suturas } \\
\text { quando necessário, reimplante, } \\
\text { contenção flexível (2 semanas), } \\
\text { prescrição de Tetraciclina por } 7 \text { dias, } \\
\text { ou Penicilina V/Amoxicilina por 4-7 } \\
\text { dias e acompanhamento da condição } \\
\text { pulpar (dentes não revitalizados ou } \\
\text { com reabsorção interna } \rightarrow \text { terapia } \\
\text { endodôntica }\end{array}$ & \\
\hline \multirow[t]{2}{*}{$\begin{array}{l}\text { Dente armazenado } \\
\text { em solução não } \\
\text { adequada e busca } \\
\text { por atendimento } \\
\text { ultrapassa } 60 \\
\text { minutos }\end{array}$} & $\begin{array}{l}\text { Rizogênese completa: lavagem com } \\
\text { soro fisiológico e imersão em fluoreto } \\
\text { de sódio a } 2 \% \text { (por } 20 \text { minutos), } \\
\text { anestesia, verificar presença de } \\
\text { fratura alveolar (reposicionar o osso, } \\
\text { se preciso), reimplante com suave } \\
\text { pressão digital, radiografia para } \\
\text { verificar posição, contenção flexível } \\
(1 \text { a } 2 \text { semanas), tratamento } \\
\text { endodôntico antes ou após o } \\
\text { reimplante (quando for após, deve } \\
\text { ser entre o } 7^{\circ} \text { e o } 10^{\circ} \text { dia. Medicação } \\
\text { com hidróxido de cálcio - trocada a } \\
\text { cada } 3 \text { ou } 6 \text { meses) }\end{array}$ & \multirow[t]{2}{*}{$\begin{array}{l}\text { Pozo et al. }{ }^{36} \text { (2006); } \\
\text { Rodrigues et al.37 } \\
(2010) ; \\
\text { Xavier et al. }{ }^{6}(2013) ; \\
\text { Veras et al.35 (2017) }\end{array}$} \\
\hline & $\begin{array}{l}\text { Rizogênese incompleta: remover } \\
\text { tecido necrosado da superficie } \\
\text { radicular (com gaze), imersão do } \\
\text { dente em fluoreto de sódio a } 2 \% \text { (por } \\
\text { 20 minutos), anestesia, remoção do } \\
\text { coágulo, reimplante, contenção ( } \\
\text { semanas), antibioticoterapia pode ser } \\
\text { considerada, e tratamento } \\
\text { endodôntico (após 7 a 10 dias) }\end{array}$ & \\
\hline
\end{tabular}

- Acompanhamento e prognóstico

O controle de dentes reimplantados deve ocorrer a partir da primeira consulta, com monitoramento clínico e radiográfico após os seguintes intervalos de tempo: 4 semanas, 3 meses, 6 meses, 1 ano e então depois anualmente ${ }^{1}$. Segundo Anderson et al. ${ }^{1}$ são indicativos de sucesso no tratamento, em dentes com ápice fechado: ausência de sintomas, mobilidade normal, som de percussão normal e radiograficamente não apresentar evidência de reabsorção ou osteíte radicular.

Em dentes com rizogênese incompleta considera - se resultados favoráveis, a constatação de: dente assintomático, mobilidade normal, som de percussão normal, radiograficamente mostrar evidências da ação de formação continuada da raiz e canal pulpar obliterado. Espera-se devolver a estética do paciente e a função, favorecendo o crescimento do osso alveolar e seu contorno. Em crianças abaixo de 15 anos, espera-se ocorrer uma 
infraposição do dente e como consequência final pode se esperar anquilose e reabsorção da raiz $^{32}$. Anquilose ou reabsorção de substituição é uma condição caracterizada pela fusão da superfície do osso e da raiz alveolar, condição que pode ser visualizada em um período de 4-8 semanas após o reimplante. $O$ dente fica imóvel e tem um som metálico a percussão, comumente é observada uma infraoclusão do dente ${ }^{7}$.

Uma das consequências do insucesso do reimplante dentário são as reabsorções inflamatórias que podem causar anquilose dentária $^{38}$. Para Andreasen ${ }^{39}$, o período em que se iniciam as reabsorções inflamatórias é de 2 a 12 semanas. Desse modo, é importante ressaltar que a espera por 1 ou duas semanas para realizar o tratamento endodôntico não está relacionada com a reabsorção, mas, provavelmente com reparação. A reabsorção inflamatória externa é caracterizada por provocar um processo inflamatório progressivo e necrose pulpar. Clinicamente o dente não responde a testes de vitalidade, apresenta descoloração na coroa, pode apresentar som à percussão, radiograficamente pode ser visto uma radiolucência ${ }^{7}$.

\section{- Papel do cirurgião-dentista para o sucesso do reimplante dentário}

No estudo de Antunes et al. $^{18}$, o conhecimento dos profissionais a respeito do modo de armazenamento do dente avulsionado foi considerado equivocado. Os autores concluíram que é evidente necessidade da busca dos profissionais por conhecimento técnico e científico sobre o tema, objetivando promover um melhor atendimento ao paciente $\mathrm{e}$ divulgação do conhecimento à comunidade. A conscientização dos profissionais da área sobre os protocolos de atendimento é de grande importância para reduzir a ocorrência de casos e promover sucesso nos tratamentos ${ }^{40}$.

Nos estudos de Antunes et al. $^{18} \mathrm{e}$ Lubaszewski et al. ${ }^{12}$, onde ambos avaliaram o conhecimento de dentistas na condução do tratamento de avulsões dentárias, odontopediatras tiveram melhores resultados do que os clínicos. Tal fato pode ser explicado pelo maior contato com esse conhecimento durante a especialização. Este achado pode refletir que disciplinas sobre 0 assunto precisam ser reforçadas durante a graduação e o incentivo a educação continuada precisa ser melhorado, já que se espera que qualquer cirurgião-dentista saiba conduzir corretamente os casos de trauma com avulsão dentaria.

CONSIDERAÇÕES FINAIS

Com base na literatura analisada e os resultados obtidos e discutidos, foi possível sistematizar as vantagens e desvantagens das substâncias usadas no armazenamento do dente avulsionado, as condutas específicas para as diferentes situações clínicas da avulsão dentária. Contudo, ressaltam-se ainda a necessidade de discussão sobre o tema na comunidade acadêmica, cirurgiões dentistas, profissionais da saúde e da educação a fim de que as decisões clínicas sejam sempre baseadas em evidências científicas para assegurar um prognóstico favorável para o paciente.

Como a maioria dos temas da odontologia, as medidas clínicas e terapêuticas para os casos de avulsão estão em evolução e passando por melhorias com o passar dos anos. É preciso mais investimento com a finalidade de disseminar e publicar a divulgação da informação correta para o público leigo, bem como fomento para revisões sistemáticas, com metanálise e estudos clínicos de qualidade para subsidiar a decisão clínica dos cirurgiões dentistas, busca de novos materiais e técnicas que proporcionem um melhor prognóstico nos casos de avulsões dentárias.

\section{REFERÊNCIAS}

1. Andersson L, Andreasen JO, Day P, Heithersay G, Trope M, Diangelis AJ et al. Guidelines for the Management of Traumatic Dental Injuries: 2. Avulsion of permanente teeth. Pediatr Dent. 2017;39:412-19.

2. Antunes DP, Chaoubat $A$, De Paula MVQ, Salgado I De O, Coelho L Da GC. Conhecimento de cirurgiões-dentistas sobre condutas clínicas nas avulsões e reimplantes dentários: estudo piloto. HU Rev. 2012;38: 45-51.

3. Souza BLM, Lopes PH De S, Nogueira EF De C, Torres BCA. Manejo de trauma dentoalveolar atípico: relato de caso. Rev cir traumatol buco-maxilo-fac.2013;13:45-50.

4. Xavier CB, De Faria GD, Vogt BF, Collares KF, Dickel R. Estudo dos traumatismos alvéolos dentários em pacientes atendidos em um setor de Cirurgia e Traumatologia Buco-MaxiloFacial. Rev Gauch Odontol. 2011;59:565-70.

5. Trigueiro M, Costa MMT De M, De Souza ICG, Leitão GLNC, Ortega A De OL. Avulsão dentária: efeito da informação na mudança de comportamento dos professores do ensino fundamental. ROBRAC. 2015;24:57-61.

6. Xavier CB, Soldati, DC, Barbin EL. Manejo das avulsões dentárias traumáticas em dentição permanente: elementos para diagnóstico, tratamento e proservação. PECOS. 2010;1(1): 1-14.

7. Moradian $\mathrm{H}$, Badakhsh S, Rahimi M, Hekmatfar S. Replantation of an avulsed maxillary incisor 
after 12 Hours: three-year follow-up. Iranian Endod J. 2013;8:33-6.

8. Rebouças PD, Moreira-Neto JJS, Sousa DL. Fatores que Influenciam no Sucesso do Reimplante Dental. Publicatio UEPG. 2013;19: 31-37.

9. Mesquita GCM, Soares PBF, Moura CCG, Roscoe MG, Paiva SM, Soares CJ. A 12-Year Retrospective Study of Avulsion Cases in a Public Brazilian Dental Trauma Service. Braz Dent J. 2017;28:749-56.

10. Coste SCC, Silva EF, Santos LCM, Ferreira DAB, Côrtes MIS, Colosimo EA et al. Survival of Replanted Permanent Teeth after Traumatic Avulsion. J Endod; 2020;46:370-75.

11. Endo MS, Kitayama VS, Queiroz AF, Pavan AJ, Pavan NNO. Conhecimento de leigos sobre a conduta emergencial frente à avulsão dental. Arq MUDI. 2014;18:65-74.

12. Lubaszewski VPA, Raldi DP, Pinto CA, Habitante SM. Avaliação da conduta emergencial em casos de avulsão dentária antes e após palestras educativas. Clín Pesq Odontologia UNITAU. 2015;7:9-19.

13. Bruno KF, De Souza BL, De Oliveira DA, De Castro FLA. Conhecimento de profissionais de Educação Física frente ao tratamento emergencial de dentes permanentes avulsionados. Rev Odontol UNESP. 2012;41: 267-72.

14. Victorino FR, Gottardo VD, Zadetto Junior R, Moreschi E, Zamponi M, Trento CL. Reimplante de dentário para o tratamento de Avulsão Dentária: Realato de caso clínico. Rev Assoc Paul Cir Dent. 2013;67:202-6.

15. Curylofo PA, Lorencetti KT, Silva, SRC. Avaliação do conhecimento de professores sobre avulsão dentária. Arq Odontol. 2012;48:175-80.

16. Costa LED, Queiroz F De S, Nóbrega CBC, Leite MS, Nóbrega WFS, De Almeida ER. Trauma dentário na infância: avaliação da conduta dos educadores de creches públicas de Patos-PB. Rev Odontol UNESP. 2014;43: 402-8.

17. Cosme-Silva L, Fernandes LA, Rosselli ER, Poi WR, Martins N Da S, Lima DC. Tooth injuries: knowledge of parentes of public school students from the city of Alfenas, Minas Gerais, Brazil. Dent Traumatol. 2018;34:93-9.

18. Antunes DP, Gonçalves MA, Antunes DP, De Paula MVQ, Leite FPP, Chaves M Das GA De M. Conhecimento dos Cirurgiões-Dentistas Sobre Avulsão Dentária. UNOPAR Cient Ciênc biol saúde. 2013;15:5-8.

19. Silva CAM, Leite G De S, Pastoriza PSR, Ferreira JMS, Guaré R De O. Conduta dos odontopediatras e clínicos gerais diante de uma avulsão traumática na dentição decídua. Odontologia. 2014;22:43-51.
20. Qian H, Ding Y, Wu Y, Li S. The effects os threen modified Hank's balanced salt solutions on root resorption of late replanted teeth. A pilot study. J Craniomaxillofac Surg. 2018;46: 808-14.

21.Poi WR, Sonoda CK, Martins CM, Melo ME, Pellizzer EP, De Mendonça MR, et al. Storage media for avulsed teeth: a literature review. Braz Dent J. 2013:24:437-45.

22. Sayão Maia SAM, Travassos RMC, Mariz EB, Macêdo S Do M, De Alencar TA. Conduta clínica do cirurgião-dentista ante a avulsão dental: Revisão de literatura. RSBO. 2006;3: 41-7.

23. Osmanovic A, Halilovic S, KurtovicKozaric A, Hadziabdic N. Evaluation of periodontal ligament cell viability in different storage media based on human PDL cell culture experiments. A systematic review. Dent Traumatol. 2018;34: 384-93.

24. Monteiro JES, De Sousa RV, Firmino RT, Granville-Garcia AF, Ferreira JMS, Menezes VA. Conhecimento de acadêmicos de Educação Física sobre avulsão e o reimplante dentário. RFO UPF. 2012;17:131-36.

25. Peixoto AC, Melo AR, Santos, TS. Transplante Dentário: Atualização da literatura e relato de caso. Rev cir traumatol buco-maxilo-fac. 2013; 13:75-80.

26. Wang G, Wang C, Qin M. A retrospective study of survival of 196 replanted permanente teeth in childre. Dent Traumatol. 2019;35:251-58.

27. Diangelis, AJ, Bakland, LK. Traumatic dental injuries: Current treatment concepts. JAMA. 1998;129:1401-414.

28. Albuquerque YT, Rosell FL, Tagliaferro EP Da $S$, Da Silva SRC. Conhecimento das mães sobre os procedimentos de emergência nos casos de avulsão dentária. RFO UPF. 2014; 19:159-65.

29. Siqueira AC, Gonçalves PE. Avulsão dentária traumática acidental: Cuidados odontológicos para o reimplante. Rev FOL Fac Odontol Lins/UNIMEP. 2012;22:47-53,.

30. Hamanaka EF, Silva VF, Poi WR, Brandini DA, Panzarini SR. Use of systemic antibiotic therapy after the replantation of avulsed permanent teeth: a literature review. Braz Dent Sci. 2017;20:12-6.

31. Kostka E, Meissner S, Finke CH, Mandirola M, Preissner S. Multidisciplinary Treatment of Tooth Avulsion Considering Different Therapy Concepts. Open Dent J. 2014;8:180-83.

32. Flores MT, Andersson L, Andreasen JO, Bakland LK, Malmgren B, Barnett $F$, et al. Guidelines for the management of traumatic dental injuries. II. Avulsion of permanent teeth. Dental Traumatology. 2007;23:130-36.

33. Najeeb S, Siddiqui F, Khurshid Z, Zohaib S, Zafar MS, Ansari AS. Effect of biphosphonates 
on root resorption after tooth replantation - a systematic review. Dent Traumatol. 2017;33: 77-83.

34. Lou Q, Zhu Y, Wang X. Fourteen Years After Delayed Replantation of na Avulsed Permanent Tooth: Clinical Features and Outcomes. J Craniofac Surg. 2019;30:692-94.

35. Veras SRA, Bem JSP, Almeida ECB, Lins CCSA. Dental splints: types and time if immobilization post tooth avulsion. J Istanb Univ Fac Dent. 2017;51: 69-75.

36. Pozo PP, Soto MJB, Troisfontaines ESE. Antibiotic prophylaxia in pediatric odontology. Ana update. Med Oral Patol Oral Cir Bucal. 2006;11:352-57.

37. Rodrigues TLC, Rodrigues FG, Rocha JF. Avulsão Dentária: Proposta de Tratamento e Revisão de Literatura. Rev Odontol Univ São Paulo. 2010;22:147-53.

38. Spinas E, Generali L, Mameli A, Demontis C, Martinelli D, Giannetti L. Delayed tooth replantation and inflammatory root resorption in childhood and adolescence. J Biol Regul Homeost Agents. 2019;33(2):623-27.

39. Andreasen JO, Andeasen FM. Fundamentos de traumatismo dental. 2. ed. Porto Alegre: Artmed; 2001.

40. Ishida AL, Endo MS, Kitayama VS, Pavan AJ, Queiroz AF, Pavan NNO. Avulsão dentária e fatores relacionados ao prognóstico: estudo retrospectivo de 13 anos. Arq MUDI. 2014; 18:17-28.

\section{CONFLITO DE INTERESSES}

Os autores declaram não haver conflitos de interesse

\section{AUTOR PARA CORRESPONDÊNCIA}

\section{Adriano Referino da Silva Sobrinho}

Universidade de Pernambuco - UPE

Rua Cícero Monteiro de Melo, s/n São Cristóvão, 56503-146 Arcoverde-PE, Brasil

Telefone: (87)996136677

E-mail: nanorssobrinho@gmail.com
Submetido em 09/05/2020

Aceito em 23/10/2020 